\title{
A mobilidade sustentável como instituição do Comum: o desafio de sua inclusão na agenda das políticas públicas do Brasil pós- COVID-19
}

Anísio Brasileiro

Programa de Pós-Graduação em Engenharia Civil, Universidade Federal de Pernambuco, Brasil.

ORCID: https://orcid.org/oooo-0oo2-1566-7241

\section{Leonardo Herszon Meira}

Programa de Pós-Graduação em Engenharia Civil, Universidade Federal de Pernambuco, Brasil.

ORCID: https://orcid.org/oooo-0oo2-3369-5801

\author{
Ligia Rabay \\ Programa de Pós-Graduação em Engenharia Civil, Universidade Federal de Pernambuco, \\ Brasil. \\ ORCID: https://orcid.org/0000-0003-0159-6953
}

\author{
Natália Cavalcanti \\ Programa de Pós-Graduação em Engenharia Civil, Universidade Federal de Pernambuco, \\ Brasil. \\ ORCID: https://orcid.org/00oo-0002-5282-5990
}

\author{
Pâmmela Roberta Gonçalves dos Santos \\ Programa de Pós-Graduação em Engenharia Civil, Universidade Federal de Pernambuco, \\ Brasil. \\ ORCID: https://orcid.org/oooo-0002-5027-4283
}

Recibido: 3 de abril de 2021. Aceptado: 18 de mayo de 2021.

\section{Resumo}

Em 2020, um Fórum de universidades públicas, em parceria com atores sociais, colocou como questão central: como inserir na agenda dos decisores políticos o tema da mobilidade sustentável, de modo que suas propostas possam ser implantadas? Este artigo busca na ciência política conceitos que permitam a construção de uma narrativa suficientemente robusta para ser assumida politicamente como agenda. Para isso, propõese a hipótese que define o espaço público das cidades como Commons ou Comum, aí 
incluídos os serviços públicos e a mobilidade urbana. Através da análise da importância das instituições e organizações da Sociedade, da identificação dos grupos de interesse e de suas lideranças e do conceito dos Commons, foram identificadas evidências que comprovam a hipótese. Conclui-se pela necessidade de repensar o papel do Estado, que passaria a ter funções de definição de diretrizes, de construção de um quadro jurídico sob o conceito do Comum, além do financiamento dos serviços e infraestruturas de transportes. A gestão da mobilidade urbana passaria a ser gerenciada por atores sociais, através de processos participativos. Para isso, é essencial que as lideranças políticas conduzam o processo político de viabilizar a agenda proposta com efetiva inclusão da sociedade na gestão dos serviços de mobilidade urbana.

Palavras-chave: Covid-19. Mobilidade sustentável. Transporte público. Instituições. Comum.

\section{Sustainable mobility as an institution of Commons: the challenge of its inclusion in the public policies agenda of Brazil post- COVID-19 ABSTRACT}

In 2020, a Forum of public universities, in partnership with social actors, proposed a central question: how to insert the theme of sustainable mobility into the agenda of policy makers, so that their proposals can be implemented? This article seeks in the political science concepts that allow the construction of a narrative robust enough to be politically assumed as an agenda. For this, it is proposed the hypothesis that defines the public spaces of cities as Commons or Common, including public services and urban mobility. By analyzing the importance of institutions and organizations of Society, the identification of interest groups and the role of their leaders and the concept of Commons, we identified evidence that proves the hypothesis. We conclude for the need to rethink the role of the State, which should assume functions of defining guidelines, of constructing a legal framework under the concept of Common, in addition to financing transport services and infrastructures. The management of urban mobility would be carried out by social actors by participatory processes. For this, is essential that political leaders conduct the process to make the agenda feasible with effective participation of society in the management of urban mobility services.

Keywords: Covid-19. Sustainable Mobility. Public Transport. Institutions. Common.

Palabras clave: Covid-19. Movilidad sustentable. Transporte público. Instituciones. Común.

\section{Introdução}

A discussão recente no Brasil acerca da sustentabilidade nos transportes públicos e na mobilidade urbana, redimensionada pela irrupção da pandemia do Covid-19, vem colocando ênfase no desafio de construir modelos de transporte público que, estruturalmente reformados, tornem-se mais sustentáveis e resilientes a crises. Assim, partindo desse objetivo de médio prazo, este artigo coloca outro desafio que é de colocar esse tema na agenda dos decisores políticos, em particular dos prefeitos municipais empossados em janeiro de 2021 para governar os mais de 5 mil municípios brasileiros.

Isso significa trazer ao debate público um dos ensinamentos centrais do Fórum promovido ao longo de 2020 pelo Programa de Pós-Graduação em Engenharia Civil da Universidade Federal de Pernambuco (UFPE), que foi a necessidade de repensar o modelo atual de planejamento urbano das cidades, em escala metropolitana, e suas interfaces com a mobilidade das pessoas. O modelo vigente é portador de desigualdades territoriais, com grandes disparidades entre ofertas de serviços urbanos 
-transportes, saneamento, habitação, educação, saúde, internet- diferenciados entre áreas centrais e periferias. A construção política de outro modelo para o planejamento das cidades e de sua mobilidade, a ser colocado na agenda pública, passa pelo entendimento e necessidade de superação da própria natureza da atual crise cíclica do modo de produção capitalista (Santos, 2000), em que as políticas praticadas nas metrópoles industriais geram desigualdades expressas na carência de serviços públicos e de suas infraestruturas.

Assim, a imensa crise sanitária provocada pelo Covid-19 traz à tona as desigualdades provocadas pela urbanização planetária em um contexto de um mundo com fluxos altamente conectados em passageiros e mercadorias, onde prevalece o que Harvey (2020) chamou de um "modo de consumismo" voltado para o fortalecimento do turismo internacional, das cadeias hoteleiras, dos aeroportos e suas estruturas, restaurantes, eventos culturais, etc. É justamente a interrupção e bloqueio desses fluxos de capitais, em um modelo econômico baseado na financeirização, que traz à tona a crise mundial e o desemprego que se agrava com a pandemia.

Uma vez que os problemas essenciais de desigualdades sociais resultantes dessa crise se manifestam nas cidades, coloca-se a hipótese do artigo, que é a definição do espaço públicos das cidades enquanto Commons ou Comum e os próprios serviços públicos que atendem às necessidades humanas, dentre os quais está a mobilidade urbana. No caso brasileiro, a mobilidade urbana é caracterizada enquanto serviço público a ser ofertado pelo Estado ou delegado à iniciativa privada por meio de contratos de concessão ou permissão, precedidos de licitação. Uma vez confirmada as evidências da hipótese, se fará necessário a redefinição do papel do Estado na gestão da mobilidade que teria funções de estabelecer as diretrizes, o quadro legal e o financiamento dos serviços de transportes, enquanto organizações da Sociedade, representadas pelos atores sociais que ficariam com a tarefa de cogestão da mobilidade urbana.

Essa hipótese se baseia no conceito de Commons ou Comum (Ostrom, 2010 e Dardot e Laval, 2017), aplicado aos espaços públicos compostos por calçadas, ruas, ruelas, bulevares e avenidas, praças, parques, passeios, canais, ilhas, ou as chamadas friches urbanas (espaços abandonados ou degradados), onde flui a mobilidade de pessoas, usando diversos modos de transporte: público, individual, ativos (bicicleta, caminhada, patinetes), a serem cogerenciados por organizações da Sociedade.

Essa mobilidade urbana entendida como um Comum deve ser reequilibrada e tornar-se acessível para todos os atores da cidade. Logo, uma vez que entendemos a mobilidade enquanto um serviço público, que utiliza os espaços públicos definidos como Comum, os serviços públicos que utilizarem esses espaços podem ser definidos também como Comum, agora dentro de uma visão de integração com outras infraestruturas urbanas e serviços públicos (habitação, saúde, educação, saneamento, energia, internet).

Para desenvolver a hipótese do artigo, será analisado o conceito de Comum, que se define enquanto um processo político, alternativo ao modo de produção capitalista e à gestão pública tradicional, capaz de superar as crises inerentes ao próprio modo capitalista de apropriação privada dos espaços públicos. O termo que passaremos a chamar de Comum baseia-se na ideia-força do autogoverno, do agir comum através de instituições criadas para essa gestão, contando com a participação essencial dos movimentos sociais e da Sociedade, na perspectiva da cogestão dos serviços públicos e da mobilidade urbana (Dardot e Laval, 2017). A expectativa do artigo é que a confirmação das evidências dessa hipótese configure uma narrativa suficientemente robusta para que os decisores públicos (suas lideranças) absorvam ou insiram o tema da mobilidade sustentável sob a ótica e influência das pessoas na agenda pública. 
Para averiguar essa hipótese, além do aprofundamento histórico do conceito de Comum, é necessário analisar o papel das instituições e organizações, segundo North (2018), os grupos de interesse (Grossman e Saurugger, 2006) e suas lideranças, que se disputam em torno da construção de narrativas que tenham força suficiente para se transformarem em agendas inseridas nas políticas dos decisores públicos.

Assim, o artigo tem por objetivo a necessidade de se construir uma narrativa suficientemente robusta capaz de sensibilizar os decisores públicos (os Prefeitos, no caso brasileiro) para inserir nas suas agendas políticas e de tomada de decisão, o tema da mobilidade sustentável, em um contexto de valorização dos espaços públicos e da própria cidade, a ser apropriada por toda a Sociedade. O artigo se coloca em uma perspectiva de construção de uma narrativa em torno do desafio de propor modelos de transportes públicos sustentáveis e resilientes alternativos às políticas de construção de infraestruturas rodoviárias e de prioridade ao automóvel nas vias urbanas. Coloca-se ainda que a grande inovação do artigo é relacionar o conceito de Comum com a gestão da mobilidade urbana, fato este não encontrado até hoje na literatura.

Para esse fim, colocam-se como objetivos específicos: i) a necessidade de repensar os transportes e a mobilidade integrados aos demais serviços públicos utilizando os espaços públicos, agora entendidos enquanto um Comum; ii) nessa perspectiva, analisar o novo papel do Estado, em seus níveis federal, estadual e municipal, na oferta de transportes baseados na prioridade ao transporte público, aos modos ativos e compartilhados, geridos por plataformas digitais e iii) daí a necessidade de repensar o modelo de planejamento e gestão das cidades em escala urbano-metropolitana, onde se coloca a chamada "cidade de 15 minutos" defendida por Anne Hidalgo em sua proposta de reeleição à Prefeitura (Mairie) de Paris (Terranova Think Tank, 2020).

O método adotado baseia-se na análise dos discursos dos palestrantes nos diversos webinários que compuseram o Fórum e dos documentos (artigos, notícias de jornais, análises) que têm circulado nesses tempos de pandemia, para verificar como esses discursos e propostas embasam a hipótese do artigo.

\section{Importância das instituições e dos grupos de interesse no espaço público}

O problema do artigo consiste então em saber como colocar o tema da mobilidade sustentável nas prioridades das agendas públicas de governos e suas lideranças. A busca de respostas a essa questão tem conduzido as pesquisas que temos realizado para o CNPq (Brasileiro, 2019) cujos resultados apontam que têm mais chance de ser bem-sucedidos aqueles projetos onde os atores representados pelos seus grupos de interesse se articulam e cooperam mais, construindo ambientes de confiança, para que o projeto, uma vez colocado nas agendas políticas e de governo, seja implementado com sucesso (Brasileiro, 1991).

\section{As instituições importam}

Entramos assim, no campo da Ciência Política enquanto área de conhecimento científico e da política pública de transportes como área específica de saber acadêmico e social. O que nos leva ao estudo do Estado e de sua relação com a Sociedade. Segundo Bobbio (2000), o termo "política" derivada de politikós, que é o adjetivo de pólis e se perpetuou no tempo a partir da grande obra de Aristóteles, intitulada "Política" que foi o primeiro tratado sobre a natureza, as funções, as divisões do Estado e suas várias 
formas de governo. Nesse sentido, as instituições da política são essenciais e, para North (2018), elas importam em muito.

Para esse artigo, alguns aspectos são importantes a ressaltar, relativos à ideia central em North (2018) de compreender as instituições como fator explicativo principal do crescimento econômico e a evolução das sociedades. São eles: i) as regras formais e informais que presidem o comportamento humano; ii) as organizações existentes e iii) a cooperação para reduzir os custos de transação.

O autor destaca que o principal papel das Instituições em uma Sociedade é reduzir a incerteza. Essas decorrem da incompletude das informações a despeito da conduta dos outros indivíduos no processo de interação humana. Mas para isso é preciso que existam regras ou normas e procedimentos para simplificar o processo e reduzir as incertezas e, com isso, estruturar as relações sociais. Portanto, as "instituições são as regras do jogo em uma sociedade ou, em definição mais formal, as restrições concebidas pelo homem que moldam a interação humana" (North, 2018: 13). Nesse sentido, Galla (2003) destaca a importância da criação das instituições eficientes na Europa e nas cidades italianas da Idade Média, o que permitiu a transição do feudalismo para o capitalismo em sua fase mercantil com o surgimento do mercado, seguindo-se daí a revolução industrial na Inglaterra.

A existência de instituições necessita da adoção de: i) regras formais - aquelas que ditam aquilo que os indivíduos são proibidos de fazer e, por vezes, as condições sob as quais se permite que alguns indivíduos exerçam determinadas atividades e ii) regras informais - códigos de conduta tácitos que respaldam e suplementam as regras formais, estando associadas a normas de comportamento, hábitos. São aquelas incorporadas nos costumes, tradições e códigos de conduta, chamadas também de restrições culturais que ligam o passado ao presente e ao futuro e nos proporcionam uma chave para explicar a trajetória da mudança histórica. Portanto, as instituições, constituem o âmbito onde se dá a interação humana, expressa por acordos formais definidos por leis e contratos entre indivíduos e informais regidos por culturas e hábitos.

Outro aspecto da teoria institucional de North (2018), diz respeito à necessidade da criação de organizações que, a exemplo das instituições, também proporcionam uma estrutura para as interações humanas. Mas é crucial distinguir esses dois conceitos. As instituições definem as regras do jogo, isto é, "a finalidade das regras é definir o modo segundo o qual o jogo é jogado" (North, 2018: 16), ao passo que nas organizações, as equipes definem que o objetivo "no âmbito daquele conjunto de regras é ganhar o jogo - mediante uma combinação de habilidades, estratégias e entrosamento, em jogo limpo e às vezes com faltas" (North, 2018: 16).

Assim, são exemplos clássicos de instituições, as Constituições ou quadros jurídicos que permitiram uma grande mudança institucional na Europa que foi a dissolução do feudalismo e do senhorialismo com o advento do capitalismo. É o caso também da criação da Constituição dos Estados Unidos que definiu a concepção do país, ou ainda as instituições podem evoluir ao longo do tempo, como se dá com o Common Law, sistema judicial desenvolvido principalmente em países anglo-saxões (North, 2018: 15).

Já as organizações abrangem órgãos políticos (partidos, senado, câmaras de vereadores, agências reguladoras), econômicos (empresas, sindicatos, cooperativas) e educacionais (escolas, universidades, centros de treinamento). As organizações agrupam indivíduos com algum propósito comum com vistas a atingir objetivos comuns. Assim, tanto o gênero de organizações que se formam como o modo segundo o qual elas evoluem são influenciados pelo quadro institucional. Assim, as interações entre Instituições e Organizações direcionam a mudança institucional. Mas se as instituições determinam 
as oportunidades em uma sociedade, as organizações são criadas para aproveitar essas oportunidades e, à medida que evoluem, alteram as próprias instituições.

Um último aspecto da teoria de North (2018) trata da cooperação. Para o autor, a teoria neoclássica tem sido importante para analisar os mercados e suas imperfeições nas sociedades desenvolvidas, mas não explica a persistência milenar de formas de trocas que se afiguram ineficientes. Suas implicações decorrem de seus pressupostos acerca de um processo de trocas sem atrito, no qual os direitos de propriedade são estipulados de modo impecável e isento de custos, com as informações sendo obtidas igualmente sem custos. Tendo como base a teoria do economista Ronald Coase sobre a "A natureza da firma" e o "problema do custo social", North (2018: 28) chega à conclusão que "nas situações em que transacionar é custoso, as instituições são relevantes".

A partir daí, North desenvolve uma Nova Teoria Institucional que coloca como central a cooperação entre os indivíduos para que os custos de transação sejam reduzidos. Sabendo que essa cooperação se dá segundo regras formais e informais a serem seguidas pelas organizações da Sociedade. Essa análise institucional de North (2018), será retomada ao final desse artigo referente: i) à necessidade de bem (re) definir no Brasil, o papel das instituições que fazem as leis -como é o caso da Constituição Federal de 1988, e legislações estaduais e municipais- ou seja, as regras do jogo onde os atores dos transportes e da mobilidade urbana atuam e ii) à redefinição ou criação de organizações encarregadas da gestão dos serviços de transportes e da mobilidade urbana, que devem contar com a presença obrigatória dos atores da Sociedade.

Mas antes, é necessário apresentar o conceito de Grupos de Interesse e a importância das lideranças que devem atuar no interior das instituições e organizações, com vistas a inserir seus projetos nas agendas dos decisores públicos.

\section{Grupos de interesse, liderança e o desafio da agenda pública}

Uma vez entendido que o desenvolvimento das Sociedades tem como norte explicativo a evolução das instituições e suas organizações, faz-se necessário registrar a importância de se levar em conta os conflitos entre os atores em defesa da inserção de seus projetos na agenda pública. Como bem mostram Aragão et al. (2017) em seus estudos sobre os Grupos de Interesse e suas diversas aplicações, a falta de vontade política é sempre alegada, com espírito misto de resignação e revolta, quando projetos e ações públicas de grande utilidade ou até de necessidade social e econômica não conseguem emplacar na agenda governamental. Essa frustração aumenta quando muitos projetos já prontos, tendo consumido tempo e recursos públicos não veem o dia, ou não conseguem entrar na agenda dos decisores políticos, constituindo, pois, o grande cemitério de sonhos que é o setor público.

Daí que o Grupo de Interesse é definido como um grupo que produz, representa e tenta impor ou defender um interesse ou uma causa no espaço público, influenciando os decisores políticos (Courty, 2006). Para isso, é essencial que o Grupo de Interesse disponha de recursos organizacionais, materiais e financeiros, de quadros profissionais competentes, além de uma liderança representativa que articule os atores, e que possua recursos políticos, isto é, acesso a contatos estratégicos, ao financiamento além de capacidade intelectual suficiente para elaborar projetos capazes de serem incorporados nas agendas públicas (Courty, 2006 e Grossmann e Saurugger, 2006).

Para que isso ocorra o Banco Mundial (2010) coloca que a construção de um Grupo de Interesse ou de uma coalizão possui diversas fases: i) a identificação de uma causa ou interesse pelo qual vale a pena lutar; ii) a construção de uma inteligência estratégica, onde se mapeiam os agentes relevantes envolvidos na causa ou interesse; iii) 
a identificação e mobilização dos interessados e a construção do movimento e sua organização; iv) a criação de credibilidade e representatividade do grupo, por meio da colocação em prática do repertório de ações; v) o crescimento do movimento e de sua força política, até à vitória em termos de influência sobre a política pública; vi) a gestão do processo de decisão e implementação das medidas que correspondem aos interesses defendidos e vii) um fator crítico de sucesso das ações promovidas pelo grupo de interesse é a comunicação.

Por outro lado, a inscrição do interesse e dos grupos que o representam, na agenda pública, não é um processo linear, mas segue, em geral, uma sequência (Aragão et al., 2020): i) um fato-evento determinado (relevante) gera ou deslancha um problema que é captado por um ator (iniciador) ou mais de um ator; daí o papel da liderança; ii) que geram uma primeira problematização (que interesses? e Como resolver?); iii) um conjunto de símbolos são mobilizados pelos atores em torno do problema, para atingir um público mais largo; iv) aqui trata-se de fazer a amplificação midiática (mídias); v) o público (a opinião pública) se envolve, participa ou acompanha; vi) são gerados projetos e alternativas de solução (ões) do problema, em função dos meios de financiamento e dos interesses dos atores e vii) o projeto se inscreve na agenda para execução e resolução do problema, após passar por uma forma jurídica aceitável.

Esse modelo sequencial depende: i) do aparelho político-administrativo-jurídico (burocracia; regulamentos, normas, cultura - regras formais e informais); ii) da condução do líder (primeiro-ministro, presidente, prefeito, senador, governador); iii) dos acordos e negociações entre Senado e Câmara Federal (cada instituição com sua lógica própria); iv) do nível de poder entre executivo, legislativo, judiciário); v) da regulação jurídica e vi) dos ciclos eleitorais (Muller e Surel, 2000).

Uma vez que é no interior das instituições e organizações que ocorrem os embates entre os Grupos de Interesse na luta para colocar seus projetos nas agendas dos decisores políticos, contando para isso com a existência de uma liderança representativa, cabe agora apresentar a arena ou os espaços onde essas lutas ocorrem. No caso deste artigo, essa luta ocorre nas cidades, nos espaços públicos disputados pelos diversos atores da Sociedade. É o que será visto a seguir, a partir de uma reconstituição do conceito de espaço público.

\section{Espaço público como lugar de interação entre atores sociais}

Para estudar esse conceito, usou-se como referência os conceitos de Paquot (2009), para o qual o espaço público evoca não apenas o lugar do debate político, da confrontação de opiniões privadas que a publicidade se esforça em tornar pública, mas também uma prática democrática, uma forma de comunicação, de circulação de diversos pontos de vista. Paquot considera que os espaços públicos são constituídos pelas ruas e praças, pátios e bulevares, jardins e parques, rios, praias e litoral, além de espaços florestais, campos, montanhas, além da rede viária e calçadas, que permitem o livre movimento de cada um. Segundo o autor, os espaços públicos têm uso muito diverso, pois põem em relação pessoas que se cruzam, se evitam, se ajudam, que conversam ou se ignoram. A noção de espaço público diz respeito à comunicação, à ideia de partilha, ligação, troca; essa comunicação necessita de vias físicas e digitais para a transmissão de mensagens que viabilizam a circulação de pessoas e bens.

A gestão desses espaços públicos constitui também o ambiente de ação dos édiles (prefeitos), engenheiros, urbanistas, arquitetos, uma vez que são lugares físicos, delimitados geograficamente, a exemplo dos canais, caminhos de ferro que ignoram fronteiras; mas são também "admiráveis instrumentos de dominação política", 
como afirma Paquot (2009) ao se referir às vias romanas com seus pavimentos tão bem construídos e mantidos pelos édiles que se ocupam também do cuidar dos edifícios sagrados.

Segundo Françoise Choay em seu livro Espacements (Choay, 2003 apud Paquot, 2009: 73), quatro grandes períodos da história ocidental caracterizam o espaço dos cidadãos: i) a Idade Média (espaço de contato); ii) a Era Clássica (espaço de espetáculo); iii) o Período Industrial (espaço de circulação) e iv) o Período Atual (espaço de conexão ou conectividade). Ocorre que esses períodos se interpenetram e se entrelaçam, e não se sucedem de forma linear. Assim, para cada uma dessas épocas, o espaço público faz referência às várias dimensões da identidade coletiva representadas por seus valores simbólicos (Billiard,1986), pois o espaço público se configura enquanto espaço de regulação e mediação simbólica de trocas sociais.

Essas trocas sociais nesse "espaço comum", entendido como "um arranjo que permite a copresença de atores sociais" (Levi e Michel, 2003 apud Paquot, 2009: 88) é objeto da ação política desses atores que compartilham ou disputam seu uso, em uma perspectiva de servir a todos, ou enquanto mercadoria a serviço do setor privado. Mas como observam os autores, o que confere ao espaço público sua importância como espaço de copresença dos atores sociais é a sua dimensão social e coletiva, de uso comum a toda a sociedade:

(...) o essencial não reside de forma nenhuma no estatuto jurídico desse território praticado por um conjunto de indivíduos isolados ou em grupo em um momento dado, mas na atividade em si que faz "coletivo" e confere a esse lugar uma dimensão social e pública (Paquot, 2009: 92).

Essa ideia do uso coletivo está presente no clássico Le droit à la ville (Lefebvre, 1968) que define o "urbano como bem supremo":

(...) O urbano, lugar de encontro, prioridade do valor de uso, inscrito no espaço de um tempo promovido ao ranking de bem supremo entre os bens, encontra sua base morfológica, sua realização prático-sensível. O que supõe uma teoria integral da cidade e da Sociedade urbana, utilizando os recursos da ciência e da arte. Somente a classe operária pode se tornar o agente, portador ou suporte social desta realização. Aqui, ainda, como há um século ela nega e contesta (Lefebvre, 1968: 35).

Assim, dois aspectos nos chamam a atenção desse texto escrito há mais de 50 anos, quando Lefebvre já percebia os sinais das transformações nos processos de urbanização das cidades no contexto da produção e reprodução do sistema capitalista: o primeiro é a elevação do urbano, da cidade, à condição de "bem supremo" onde todos têm direito à moradia, escola, saúde, trabalho, repouso, cultura; o segundo é o papel que ele reservava à classe operária à época.

Dessa forma questiona-se se hoje esse papel não passaria a ser exercido pelos setores precarizados da Sociedade, uma vez que, para os objetivos do artigo, parte dos espaços públicos estão localizados nas cidades (ruas, avenidas, ruelas, parques, áreas comuns). Trata-se assim, como bem interpretou Harvey (2011: 8) de "um direito coletivo mais que individual, porque, para mudar a cidade, deve-se necessariamente exercer um poder coletivo sobre os processos de urbanização". Daí vale o questionamento sobre se o conceito de Commons ou Comum está em sintonia com a concepção de direitos à cidade, enunciada por Lefebvre e muito bem interpretada por Harvey. Havendo a necessidade do exercício de um "poder coletivo", para que se defina a própria cidade enquanto um Comum. Assim: 


\begin{abstract}
(...) As cidades são um bem comum em permanente mudança e, a seu modo, bens únicos. Já temos as reconhecidas cidades históricas, tratadas como patrimônio cultural da humanidade. Mas as cidades, todas, são bens comuns, bens de todos(as) os(as) seus(suas) moradores(as). Por isso, é legítima a reivindicação do direito à cidade para todos(as) que nela vivem. Não basta considerar as vias de comunicação, as ruas e avenidas e as praças e parques como bens públicos fundamentais, como os únicos bens comuns das cidades. As capacidades aí existentes, as instituições criadas ao longo do tempo, a sinergia criadora do coletivo, enfim, são muitos os aspectos que tornam a cidade um bem coletivo, comum, de todos e todas. Seu usufruto coletivo, o compartir a cidade, só aumenta seu valor como bem comum (Passerelle; www.coredem.info, №6, 06/2012).
\end{abstract}

Então, a seguir será visto o que se pode entender como bem comum.

\title{
A Instituição Do Common (Comum) Enquanto Processo Político
}

A ideia a ser desenvolvida é que a cidade e seus espaços públicos pode ser definida enquanto um Common, um Comum, com todas as implicações que daí decorrem, como se verá a seguir neste artigo.

O primeiro autor que se destaca nesta seara é Elinor Ostrom (Ostrom, 2010) com seu estudo sobre a governança dos bens comuns. No início dos anos 1960, seus estudos partiram de um problema ligado à infiltração de água salgada no lençol aquífero de uma região em Los Angeles, Califórnia. A ampliação de suas pesquisas e de outros colegas, mostraram que medidas institucionais tiveram efeitos positivos sobre a gestão dos recursos hídricos.

Nos anos 1980 suas pesquisas se ampliaram e foram apresentadas em um painel na Academia Nacional de Ciências (1985) sobre a gestão de recursos de propriedade comum, onde foram identificadas as propriedades físicas dos recursos, as regras utilizadas para regulamentar os acessos e sua utilização, os tipos de interação que daí resultaram. Nos anos seguintes, Ostrom e sua equipe recensearam mais de 5.000 experiências de gestão de recursos comuns no mundo inteiro, sua sistematização e metodologias de análise resultando no livro Gouvernance des biens communs (2010), (no original, Governing the Commons. The Evolution of Institutions for Collective Action, 1990). Os resultados de suas pesquisas lhe renderam o Nobel da Economia em 2009.

Segundo Ostrom (2010: 44), o termo "recurso comum" designa um sistema de recursos suficientemente importante para que seja muito custoso (mas não impossível) excluir seus beneficiários potenciais do acesso aos benefícios ligados à sua utilização. Entre os sistemas de recursos comuns, são citados notadamente os ambientes de pesca, lençóis freáticos, campos para pastagens, canais de irrigação, pontes, garagens de estacionamentos, sistemas computacionais, bem como lagos, oceanos, atmosfera e outras massas de água.

Assim, Ostrom (2010: 45) se interessa em saber como se dá o acesso a um recurso comum por um só indivíduo, um conjunto de indivíduos ou empresas que passam a ser chamados de "apropriadores" para designar pescadores, pessoal de irrigação, viajantes, ou qualquer um que se apropria de unidades de recursos de um certo tipo de sistema de recursos; bem como quais são as regras existentes para essa apropriação, as sanções para quem não as cumprir e os resultados obtidos da gestão comum dos recursos. 
A partir das pesquisas de Ostrom (2010), uma literatura abundante apareceu a exemplo do dossiê publicado pela Revista Métropolitiques, intitulado Les comuns urbains: nouveau droit de cité? (Revue Metropolitiques, 2019), onde Desgoutte (2019) ressalta três características essenciais definidas nas pesquisas de Ostrom (1990): i) um recurso espacial - espaço disponível; ii) uma comunidade construída em torno do compartilhamento desse recurso e exercendo um direito de gestão sobre ele e iii) regras elaboradas pela comunidade afim de assegurar a preservação e garantir o acesso a todos, aos usos, em uma lógica de autoorganização. Ou ainda, nesse mesmo dossiê, Brossaud et al. (2019) afirmam que:

A noção de Common traduz um interesse crescente da sociedade civil para produzir, gerir e partilhar recursos materiais e imateriais de forma colaborativa e aberta (...) ao mesmo tempo em que se desenvolve na sociedade civil novas iniciativas visando produzir, gerir e compartilhar recursos materiais (água, sementes, máquinas, espaços, etc.) e imateriais (softwares, códigos genéticos, dados numéricos), respondendo ainda às aspirações de coletivos oriundas da economia colaborativa, digital e da ecologia: jardins compartilhados, habitações participativas, cartografias livres, tiers-lieux, fablabs, moedas locais, comunidades de defesa do patrimônio, energia partilhada, conteúdos educativos abertos e troca de saberes (...) (Brossaud et al., 2019).

Os segundos autores destacados são Dardot e Laval (2017), que afirmam:

O futuro parece bloqueado. Vivemos esse estranho momento, desesperador e preocupante, em que nada parece possível. A causa disso não é mistério e não decorre da eternidade do capitalismo, mas do fato de que este ainda não tem forças contrárias suficientes diante de si. O capitalismo continua a desenvolver sua lógica implacável, mesmo demonstrando dia após dia uma temível incapacidade de dar a mínima solução às crises e aos desastres que ele próprio engendra (Dardot e Laval, 2017: 11).

Nesse contexto, o conceito de Comum é apresentado como uma alternativa ao modelo capitalista de desenvolvimento, a partir de uma nova visão voltada para o agir comum em que novas instituições sejam criadas ou repensadas à luz de seus princípios. Embora trate-se de um conceito que tem suas origens na própria passagem do feudalismo para o capitalismo, nos anos recentes o Comum ressurge a partir das lutas dos movimentos sociais nos últimos 20 anos, onde um leque difuso de reivindicações podem ser sintetizadas na luta por democracia e pela redução das desigualdades ocorrendo em espaços públicos dando-lhes um caráter simbólico de espaços de resistência comum, refletindo nas palavras de Occupy: "o descontentamento geral com o sistema capitalista que, é claro, adquire diferentes formas aqui e ali” (Occupy, 2012: 21).

Essas lutas sociais recentes que ocorrem desde a primeira década do Século XXI (Occupy, 2012), iniciado com a Primavera de Árabe, com o movimento dos indignados na Espanha, se estende ao Occupy Wall Street nos Estados Unidos e chega ao Brasil com as jornadas de junho 2013. Dentre as várias razões explicativas desse movimento social, Braga (2017) destaca que ele ocorreu em um contexto de:

(...) aprofundamento da crise da globalização, assim como suas implicações sobre o regime de acumulação pós-fordista e financeirizado vigente no país em termos de desaceleração do ritmo de crescimento econômico" (Braga, 2017: 225).

Assim, para Dardot e Laval (2017):

(...) essas lutas permitem "identificar no princípio político do comum o sentimento dos movimentos, das lutas e dos discursos que, nos últimos anos, se opuseram à racionalidade neoliberal em várias partes do mundo (Dardot e Laval, 2017: 19). 
Mas voltemos às origens do conceito e vejamos como ele surge. Segundo Dardot e Laval (2017: 25), a expressão Comum se origina do termo latino múnus -fenômeno social específico -que se refere a um tipo particular de prestações e contraprestações, ou a funções, tarefas, encargos, obras, ações, a serem cumpridos, tendo a ver com reciprocidade, reconhecimento, dever e dádiva. Por sua vez, a expressão mutuum deriva de múnus, designando prestações e contraprestações referentes a toda uma comunidade (um municipium) que exprime a estrutura política de uma cidade formada por cidadãos (munícipes). Assim, o Comum ou Communis, expressão latina, designa certa obrigação no exercício da responsabilidade pública. Deduz-se daí, que o termo Comum expressa o princípio político da "coobrigação", onde todos estão juntos, no "agir comum" na realização de uma mesma tarefa, tendo como referência normas gerais jurídicas oriundas das instituições e organizações que regulam suas ações.

Da mesma forma, o termo de origem latina Comum (de múnus) tem seu correspondente grego (koinón) ou "pôr em comum" (koinónein) em Aristóteles: são os cidadãos que deliberam em comum para determinar o que convém a cada cidade, deliberando segundo a legislação, costumes e regras de vida. Em síntese, Dardot e Laval (2017: 25) definem o "princípio político" do Comum nos termos seguintes: "existe obrigação apenas entre os que participam de uma mesma atividade ou de uma mesma tarefa". Afirmam ainda que essa concepção é submetida, do ponto de vista histórico, às dimensões teológicas (o Comum como finalidade suprema das instituições políticas e religiosas), filosófica (o Comum associado ao Universal, o que é comum a todos) e jurídica (onde os movimentos "altermundialistas" o associam aos "bens comuns mundiais" como o ar, água, clima, florestas, mares, rios, conhecimento...).

Não se trata aqui de aprofundar o conceito para o qual existe vasta literatura, mas de focar na ideia do Comum enquanto "princípio político" que se coloca contrário às teses neoliberais ligadas por exemplo, aos processos de apropriação dos espaços públicos pelos poderes privados e estatais. A grande tarefa a que se propõem os autores é de construir em toda parte, uma política do Comum, enquanto forma institucional de autogoverno, entendido enquanto "governo dos homens, das instituições e das regras que eles adotam para organizar suas relações" (Dardot e Laval, 2017: 485), fazendo-se necessário para isso, a criação de:

(...) instituições de autogoverno que possibilitem o desenvolvimento mais livre possível desse agir comum, dentro dos limites estabelecidos pelas sociedades, isto é, conforme as regras de justiça estabelecidas por elas e com as quais elas estarão der acordo (Dardot e Laval, 2017: 486).

Portanto, o "princípio político" do Comum é o da "coobrigação" baseada na "codecisão" e na "coatividade" que se traduz no "autogoverno" dos Comuns, que abram espaço para os usuários e cidadãos envolvidos nos processos de decisão sobre políticas e prioridades de financiamento de projetos. Ressalte-se que os autores não acreditam no papel de salvação do Estado mundial, pois "nenhum grande Leviatã global conseguirá jamais controlar a força centralizadora do capital mundial” (Dardot e Laval, 2017: 486). E afirmam ainda os autores que, "se esse grande Leviatã tivesse de surgir um dia -o que não é nada evidente-, ele nada mais seria que resultado da governança neoliberal atual, em versão mais concentrada e ainda mais violenta" (Dardot e Laval, 2017: 487). Daí por que o foco do conceito se volta para as lutas sociais em torno da defesa de reivindicações emanadas dos movimentos sociais.

Em síntese, os autores constroem as teses do Comum a partir de sete proposições, detalhadas no livro Dardot e Laval (2017), onde se coloca o princípio de transformação social: 1) para afirmar-se a oposição entre o novo direito de uso e o direito de propriedade; 2) estabelecendo que o Comum é o princípio da emancipação do trabalho; 3) 
e que a empresa é Comum e a associação devem predominar na esfera da economia. Afirma-se ainda: 4) a necessidade de refundar a democracia social e 5) transformar os serviços públicos em verdadeiras instituições do Comum; tornando daí, necessário, 6) a criação de verdadeiras instituições Comuns mundiais e para que isso aconteça, se faz necessário e 7) inventar uma federação dos Comuns. Para os objetivos do artigo, analisemos a proposição cinco que trata da transformação dos serviços públicos em Comum.

Assim, se coloca o questionamento sobre se os serviços públicos são instituições da Sociedade ou instrumentos do poder público. Essa é uma questão de natureza social essencial que os autores colocam, pois se a pandemia atinge a todos, ela impacta de maneira muito mais intensa os segmentos mais vulneráveis da população em termos de acesso aos serviços públicos de saneamento básico como abastecimento d'água e esgotos sanitários, energia, habitação, internet, transportes. Assim, qualquer alternativa de modo de vida pós pandemia passa de forma obrigatória pela qualidade dos serviços públicos.

Como bem mostram os autores, os serviços públicos devem ser serviços comuns da Sociedade, mas só podem se desenvolver e mesmo serem ofertados com qualidade através do Estado, representado pelos organismos de governo. Esse duplo significado lhes confere um lugar de tensão permanente, de palco de lutas e conflitos entre atores. Assim, os autores se posicionam em defesa dos serviços públicos contra as políticas neoliberais que, em todo o mundo, têm levado à precarização dos empregos públicos, ao enfraquecimento da capacidade de negociação e, sobretudo, de defesa dos princípios constitucionais que regem esses serviços, ocasionados também pela ausência de concursos públicos e perda de competências para o adequado exercício da regulação pública, isso em especial no caso brasileiro.

Para transformar os serviços públicos para que eles passem a ser instituições do Comum os autores colocam as seguintes condições:

1) Mudar a concepção do Estado que deixaria de ser "uma gigantesca administração centralizada" (Dardot e Laval, 2017: 546), proprietária dos serviços públicos, para passar a ser "o sumo garantidor dos direitos fundamentais dos cidadãos, no que diz respeito à satisfação de necessidades consideradas coletivamente essenciais, enquanto a administração dos serviços seria entregue a órgãos dos quais fariam parte não só representantes do Estado, mas também trabalhadores e usuários-cidadãos" (Dardot e Laval, 2017: 547). Não se trataria do Estado deixar de ter função, ou de se desobrigar de ofertar os serviços públicos à população, mas ao contrário, citando León Duguit, famoso jurista francês, Dardot e Laval colocam que o "serviço público é uma obrigação positiva do Estado" (Dardot e Laval, 2017: 548).

2) Os serviços públicos continuam a ser ofertados pelo Estado, mas seriam criados "órgãos democráticos que dessem aos profissionais - mas também aos cidadãos a quem se destinam esses serviços- direito de intervenção, deliberação e decisão, evidentemente dentro do respeito às leis gerais e do sentido da missão do serviço público" (Dardot e Laval, 2017: 553). Os profissionais a que se referem os autores são aqueles agentes públicos, dotados de competência e formação adequada que, imbuídos pela noção de representantes do poder público, protegidos por um estatuto próprio, fariam a comunicação, a interface ou a integração com a população para a definição da oferta adequada dos serviços públicos. Caberia, portanto, ao Estado o papel de "cuidar da coordenação dos serviços públicos, de sua conformidade com o direito, mas deveria saber.

3) Delegar a entidades autônomas e conceder a organismos regionais e locais a execução dos serviços públicos" (Dardot e Laval, 2017: 550). 
É importante registrar que os autores desenvolvem o conceito de Comum em sua perspectiva histórica e elaboram sete proposições temáticas sobre a implantação do processo político do Comum em todas as áreas da Sociedade, e não apenas em um setor, como destacamos aqui o exemplo dos serviços públicos, objeto do interesse do presente artigo. Ou seja, é um conceito teoricamente sustentável e que se baseia em experiências de lutas concretas da Sociedade, a exemplo da Commune de Paris de 1871, um dos exemplos mais avançados de autogoverno que se tem conhecimento.

\section{Experiências que apontam para a instituição do Comum nas cidades}

O objetivo deste ítem é mostrar a existência de experiências concretas nas cidades que evidenciam a adoção do princípio político da gestão dos serviços públicos enquanto instituição do Comum. São apresentadas as experiências de gestão das águas das cidades de Nápoles e Paris, que mostram que é perfeitamente possível a adoção de um outro modelo de gestão e planejamento das cidades.

No caso de Nápoles, Dardot e Laval (2014: 554) colocam que "a municipalização da gestão da água em Nápoles é, sem dúvida alguma, o exemplo mais impressionante de criação de Comuns locais ou, mais exatamente, de serviços públicos locais governados como Comuns“. Já Broca (2017) coloca que na Itália o interesse pelo conceito de bens comuns ressurgiu a partir da comissão criada em 2008, pelo governo de Romano Prodi, e presidida pelo jurista Stefano Rodotà. A comissão propôs definir os comuns como "coisas que dependem do exercício dos direitos fundamentais e do livre desenvolvimento da pessoa".

Sobre a titularidade dos serviços, Broca (2017) cita Ugo Mattei (professor e membro da Comissão Rodotà, que afirma que a "pessoas jurídicas públicas ou privadas", o estatuto dos titulares desses bens -seus "proprietários"- pouco importa. Nesse contexto, Broca (2017) ressalta que a comissão insistiu, por outro lado, no fato de que os recursos devem ser gerenciados conforme sua função, para permitir o exercício de um direito. Assim, qualificar a água de "bem comum" significa que sua distribuição, seja quem for o ator que a organize, deve garantir o acesso de todos a uma água de boa qualidade e suficiente.

O autor ainda coloca que na base dos trabalhos desenvolvidos pela comissão de Rodotà, muitos movimentos sociais e políticos transalpinos se apoderaram da noção de bem comum para denunciar o setor privado e o Estado neoliberal, igualmente incapazes de satisfazer as necessidades coletivas fundamentais. Valendo-se desse princípio, 25 milhões de italianos (dos 27 milhões de votantes) se pronunciaram em junho de 2011 no referendo contra a privatização dos serviços públicos locais de fornecimento de água potável (Broca, 2017).

Em 2013, como resultado do plebiscito, foi criada, a Acqua Bene Commune Napoli, governada por representantes dos usuários, associações ambientalistas, movimentos sociais e organizações dos trabalhadores presentes nos conselhos administrativos e de fiscalização, juntamente com especialistas e representantes da prefeitura (Dardot e Laval, 2014: 557).

Com relação à elaboração do quadro teórico dos Commons encontramos em Ugo Mattei (2011) que "importa então desenvolver uma elaboração teórica, acompanhada de uma defesa militante, tratando os bens comuns como uma categoria dotada de uma autonomia jurídica constituindo uma solução de trocas tanto em relação à propriedade privada quanto à propriedade pública" (Mattei, 2011). Dardot e Laval 
(2017: 554) fazem referência a essa nova modalidade jurídica como o princípio que os orientou, pois consiste no fato de que bens comuns como a água, mas também o conhecimento, a cultura, a educação, o mar ou a internet, pressupõem um governo não mais nos moldes do direito público clássico e das formas instituídas na gestão da propriedade pública, mas de uma "democracia ativa", único caminho para sair da crise da democracia representativa.

Assim, observamos que clarificar o conceito de Comum em sua dimensão jurídica é essencial para o passo seguinte, que é a sua posta em prática. Assim, LucarellI (2018) desenvolve argumentos para a construção da categoria jurídica dos bens comuns, definidos pela Comissão Rodotà como sendo os rios e suas fontes, lagos e outras zonas aquáticas, o ar, os parques definidos pela lei, as florestas e zonas montanhosas, o mar, a fauna silvestre, os sítios arqueológicos culturais e ambientais e outras paisagens protegidas. O Relatório define ainda três tipos de bens: i) bens de pertencimento público que satisfazem o interesse geral e estão nas prerrogativas do Estado tais como as obras destinadas à defesa, as praias, as redes rodoviária e ferroviária, os aquedutos, portos e aeroportos nacionais e internacionais; ii) bens públicos sociais destinados a satisfazer os direitos civis e sociais das pessoas (hospitais, escolas, creches, redes locais de serviço público e iii) bens públicos mercantis que não entram nas categorias precedentes que podem ser geridos por organismos públicos com instrumentos de direito privado.

Assim, Lucarelli (2018) chama a atenção que a comissão definiu essa nova categoria jurídica, chamada de bens públicos sociais ou Commons (biens communs, Comum) que caracterizam a função social da propriedade pública e o papel das comunidades, entendidas enquanto "uma comunidade composta de sujeitos profundamente diferentes e ligados pela exigência comum de se beneficiar ou se prover do bem".

Lucarelli (2018) complementa que os bens comuns (Comum) "devem se beneficiar de uma proteção constitucional", o que significa efetuar adaptações na própria Constituição do país, naqueles artigos que tratam das formas e possibilidades de participação das comunidades de trabalhadores na gestão das empresas. Trata-se, portanto, de "pensar na hipótese de modificação da Constituição italiana (notadamente seu artigo 42) a fim de reconhecer e de garantir os bens comuns, claramente identificados como bens inalienáveis, imprescindíveis e indescritíveis...."

Seguindo para o caso de Paris, Kishimoto et al. (2020) registra a existência de ampla literatura sobre o tema da municipalização dos serviços públicos em todo o mundo. Assim, para entender melhor como se deu esse processo construtivo ressaltamos a entrevista concedida por Anne Le Strat, Presidente de Eau de Paris em 2015, a Olivier Petitjean, publicada no capítulo 5 de Shimoto et al. (2015) e na publicação $L^{\prime} e a u$ de Paris, Retour vers le public (Sindi, 2014).

Até 2010 o serviço de água de Paris era delegado a empresas privadas, através de três contratos de serviços públicos: na rive gauche (lado esquerdo) do rio Sena, havia dois contratos com as empresas privadas Suez e Veolia; na rive droit (lado direito) um contrato com uma empresa de economia mista onde a cidade de Paris era majoritária e contando ainda com a presença de Suez e Veolia. Quando o socialista Bertrand Delanoé assumiu a Prefeitura de Paris em 2001 (tendo sido reeleito em 2008), ele e seu gabinete estavam convencidos em termos técnicos e econômicos, que um operador único era a melhor opção para a gestão da água da cidade. Ademais, do ponto de vista político, a municipalização do sistema de águas representava um divisor de águas em relação aos prefeitos (Maires) precedentes da capital, Jacques Chirac (que foi Presidente da República) e Jean Tiberi. Essa municipalização se inseria em uma política municipal mais ampla de reforçar os serviços públicos, o que o Prefeito Delanoé o fez em seus dois longos mandatos à frente de Paris, de 2001 a 2014 (Shimoto et al., 2015). 
Um ponto essencial para o sucesso da (re) municipalização consistiu na relação de confiança entre o Prefeito e Anne Le Strat que conduziu o processo e foi a Presidente da nova empresa Eau de Paris, criada em 2010. Após sua criação houve um período de transição de dois anos, em termos da gestão de pessoal das empresas privadas para a nova empresa pública, da apropriação dos sistemas de informação e da operação do serviço. Nos anos seguintes os relatórios da Chambre de Comptes (Corte de Contas) foram bastante positivos, observando uma diminuição do preço da água para os consumidores com a manutenção de um plano audacioso de investimentos na infraestrutura. A Presidente Anne Le Strat destaca na entrevista aspectos inovadores da gestão da nova empresa pública, relativa à participação da Sociedade nas decisões através dos usuários e associações, junto com o próprio pessoal interno, além de parcerias com agricultores para cuidar da qualidade da água nas fontes, tendo sido assinado uma cooperação com atores da região para a economia da água. Os desafios maiores são relativos ao financiamento da operação, havendo de se destacar os usuários domésticos, dos usuários comerciais e econômicos que devem ser chamados a pagar mais pelo uso da água.

Assim, como primeira grande inovação na perspectiva dos Commons, a nova empresa Eau de Paris criou um Conselho de Administração com representação dos atores da Sociedade, destacando vereadores (élus) de todas as correntes políticas representadas no Conselho Municipal, do pessoal da Águas de Paris, de associações de usuários, e profissionais qualificados em áreas de meio ambiente, pesquisa e gestão.

Ademais, duas outras inovações ocorreram apenas dois anos após a criação da nova empresa. A primeira foi a assinatura do Contrato de Objetivos entre a Cidade com duração de cinco anos entre a municipalidade de Paris e a nova empresa gestora que define seus objetivos e metas a cumprir (com indicadores de gestão a cumprir) além do plano de investimentos a executar no período do contrato. A segunda foi a criação do Observatório Parisiense de Água (L'observatoire parisien de l'eau), constituído por uma comissão não ligada à municipalidade dedicada aos problemas e da água e saneamento e suas políticas, composta por inúmeros atores de perfis os mais variados. Após 2013, o Presidente do Observatório passou a ser alguém de fora da cidade de Paris.

\section{A mobilidade sustentável como um comum e sua inserção na agenda política dos prefeitos}

\section{O conceito de mobilidade sustentável segundo Banister (2008)}

O conceito de mobilidade sustentável surgiu em 1992, portanto há 30 anos (Holden et al., 2019) no contexto dos grandes marcos do desenvolvimento sustentável. Em 2020, surgiu outro artigo sobre grandes narrativas para a mobilidade sustentável (Holder et al., 2020) onde é ressaltada a ideia do escritor Yuval Noah Harari, sobre a importância da cooperação que seria "uma misteriosa cola que permite aos humanos prosperarem, pois quando as pessoas imaginam coletivamente essas ideias, a história muda”. Mas essas ideias precisam de narrativas capazes de realizar transformações na sociedade. Uma das mais importantes é a narrativa em torno da mobilidade sustentável (Holder et al., 2020) que aborda três imperativos do desenvolvimento sustentável: i) satisfazer as necessidades humanas; ii) garantir justiça social e iii) respeitar os limites ambientais.

Esses três imperativos têm como base a definição de Banister (2008) para mobilidade sustentável, aquela que fornece um paradigma alternativo aos modelos clássicos de planejamento de transportes, pois se articula em torno de uma visão de cidades policêntricas com hierarquias claras que permitem a existência de viagens de proximidade para o qual o carro não é necessário, pois estas podem ser feitas por bicicleta ou caminhada. 
O foco dessa narrativa seria de projetar cidades em uma escala onde as pessoas não precisem possuir um carro. Para isso, algumas ações essenciais são destacadas pelo autor tais como a promoção do uso de bicicletas e caminhadas; a redução da velocidade do tráfego, a valorização dos espaços públicos, tornando-os agradáveis para as pessoas, e ampliando esses espaços para o transporte público.

Um aspecto central colocado por Banister (2008) e que tem forte relação com o conceito do Comum estudado nesse artigo, refere-se à necessidade de participação da Sociedade nas decisões de políticas de transportes, através da conscientização, da difusão da informação, da comunicação ampla e transparente, do uso de tecnologias da informação, do adequado gerenciamento da demanda que permita às pessoas perceberem melhorias da qualidade ambiental, para que se possa alcançar a mobilidade sustentável. Ressalta o autor que somente com o envolvimento ativo dos usuários dos transportes, da construção de amplas coalizões entre especialistas, pesquisadores, profissionais de engenharia, arquitetura, formuladores de políticas, associações ambientalistas e de usuários, um verdadeiro debate pode ocorrer em torno da mobilidade sustentável.

\section{Serviços públicos e mobilidade sustentável como um Comum}

Vimos que uma característica essencial da concepção do Comum é o envolvimento dos atores interessados nos processos de decisão em políticas de transportes e na implantação de ações voltadas para a mobilidade sustentável. Essa concepção está em sintonia com o que propõe Banister (2008) na construção da narrativa da mobilidade sustentável: "para que uma cidade sustentável e acessível se torne uma realidade requer o apoio do cidadão ativo e novas formas de comunicação entre especialistas e cidadãos, por meio de novos fóruns para discussão e o envolvimento de todas as principais partes interessadas". E complementa: "o planejamento do transporte deve envolver as pessoas... para que haja uma compreensão da lógica por trás das mudanças políticas e as mudanças comportamentais que se sucedem".

Nesse processo participativo, a aceitabilidade pública é crucial para a implementação bem-sucedida dessa mudança radical e deve envolver a comunidade e as partes compromissadas com o processo de discussão, da tomada de decisão e da implementação de ações concretas nas cidades. Assim, o paradigma da mobilidade sustentável se move em direção a um sistema de planejamento baseado em objetivos, com vistas a implementar uma gama de intervenções políticas, mas com um importante elemento adicional, o apoio de todas as partes interessadas. No entanto, apesar das medidas necessárias para implementar a mobilidade sustentável sejam por demais discutidas e conhecidas, ela não consegue se tornar realidade. Registros na literatura listam as barreiras à sua implementação e tentam explicar por que a mobilidade sustentável não é alcançada. Discute-se sobre a necessidade da conscientização da Sociedade, de mais informação, educação, uso das mídias e publicidade, porém sempre aparece alguma razão para sua não implementação (OECD, 2002).

Para tentar melhorar a aceitabilidade pública, Banister (2008) propõe quatro tipos de ações voltadas para a promoção da mobilidade sustentável: reduzir a necessidade de viajar, promover uma mudança modal, reduzir as distâncias de viagens através de política de uso do solo e promover a inovação tecnológica, principalmente em busca de eficiência ecológica e no sistema de transporte. $\mathrm{O}$ autor também salienta meios inovadores pelos quais as pessoas podem se envolver na defesa da mobilidade sustentável, destacando-se: aceitabilidade pública, transporte saudável, efeitos de demonstração e promoção de marketing individual. Os princípios de um paradigma de mobilidade 
sustentável precisam então combinar as ações descritas acima, a busca de aceitabilidade pelo público, aliado com uma série de medidas políticas, quatro delas sendo aqui destacadas pelo autor:

a) Fazer o melhor uso da tecnologia, incluindo investimentos em tecnologia nos sistemas de transporte, sistemas de informação, orientação industrial sobre prioridades de inovação tecnológica, a exemplo de veículos híbridos, combustíveis alternativos. Para o público essas opções não são polêmicas, pois vão possibilitar a que suas atividades ocorram com o mínimo de mudança. Embora essas inovações tecnológicas precisem apontar mudanças comportamentais na direção da transição ecológica;

b) Regulamentação e preços significam que os custos externos de transporte individual devem ser refletidos nos custos reais de viajar através de preços de combustíveis mais altos ou por meio de alguma forma de cobrança ao usuário da via. O gerenciamento da demanda reduz congestionamentos e melhora a qualidade ambiental, mas requer apoio público para funcionar de forma eficaz. Isso ajudaria a reduzir o número de viagens, as distâncias da viagem, a alterar compartilhamentos modais e a promover mais veículos eficientes;

c) O desenvolvimento do uso do solo, incluindo planejamento e regulamentações, precisa ser integrado, de modo que a implementação de medidas físicas e padrões de desenvolvimento sejam usados para apoiar distâncias de viagem mais curtas. Níveis aprimorados de proximidade ajudariam a reduzir as distâncias percorridas e contribuiriam para a redução de viagens e mudanças nas divisões modais;

d) Informações pessoais claramente direcionadas, incluindo pressões sociais, conscientização, demonstração, persuasão e o marketing individual também é crucial.

Para Banister (2008), os elementos-chave na busca da aceitação pública da mobilidade sustentável apresentam algumas estratégias já adotadas por cidades preocupadas com o tema. Deles se destacam estratégias de: i) disponibilizar informações inclusivas e claras por campanhas de mídia sobre os benefícios econômicos, sociais e de saúde para as pessoas, aumentando o nível de consistência entre expectativas, sacrifícios e resultados; ii) graduar as medidas polêmicas em estágios, de forma que os resultados das ações reforcem opiniões positivas e encorajem avanços ainda a realizar; iii) de estabelecer uma visão holística que integre a tomada de decisão entre setores, assim, medidas de incentivo, tais como, regulamentações e subsídios para adoção de tecnologias ambientalmente eficientes devem ser consistentes no médio e longo prazos e reforçar o discurso público com os resultados produzidos; e iv) Assegurar que as medidas tomadas levem em conta a adaptabilidade do comportamento dos indivíduos assegurando-se avaliação permanente dos resultados, ajustando assim, as situações onde os resultados não forem eficazes face às expectativas.

\section{Conclusões}

$\mathrm{O}$ artigo tem como objetivo refletir sobre os resultados do Fórum realizado pela Universidade em 2020, buscando respostas para as cidades e sua mobilidade durante e após a pandemia da Covid-19. Assim, o artigo focou no desafio de construir modelos de transporte público que, estruturalmente reformados, tornem-se mais sustentáveis e resilientes a crises. Ao partir desse objetivo de médio prazo, este artigo propôs outro desafio que é o de colocar esse tema na agenda dos decisores políticos, em particular dos prefeitos municipais empossados em janeiro de 2021 para governar os mais de 5 mil municípios brasileiros. Para isso, se colocou a necessidade de elaboração de uma narrativa que fosse suficientemente robusta para ser inserida na agenda dos decisores políticos. 
Essa narrativa parte da hipótese do artigo, que é a definição do espaço público das cidades enquanto Commons ou Comum, bem como os próprios serviços públicos que atendem às necessidades humanas, dentre os quais a mobilidade urbana. Esperamos ter demonstrado a existência de evidências suficientes para confirmar essa hipótese. Assim, a narrativa proposta se constrói em torno de cinco eixos temáticos assim definidos: primeiro, registra-se a importância das instituições e de suas organizações necessárias à gestão da cidade e dos serviços públicos. Na prática, trata-se aqui da redefinição do papel do Estado na gestão da mobilidade urbana, que passa agora a exercer funções de definir diretrizes nacionais de políticas de transportes, de estabelecer um novo quadro jurídico para classificar os serviços públicos entendidos enquanto instituições do Comum e para financiar o próprio sistema de transportes. Às autoridades de tutela locais -os municípios e consórcios metropolitanos -caberá o papel de criar organizações (ou reorganizar as existentes) para o exercício da gestão da mobilidade urbana em parceria efetiva com representantes da sociedade.

Segundo, as instituições como o Estado e essas organizações de gestão não são, em si, proprietários dos serviços de transportes e, portanto, não devem responder sozinhas (ou não tomam decisões) sem consultar os atores da Sociedade. Trata-se aqui de reposicionar a gestão da mobilidade para envolver os atores sociais, no sentido exposto por Banister (2008) e na perspectiva do Comum enquanto "princípio político", baseado na ideia de "codecisão", no sentido proposto por Dardot e Laval (2017). Apresentam-se no artigo, evidências de processos participativos nos exemplos da remunicipalização da água em Paris e Nápoles, para o qual são necessárias pesquisas aprofundadas sobre os grupos de interesse atuando nessas experiências.

Terceiro, um programa com propostas concretas deve ser objeto das ações das organizações do Comum na gestão da mobilidade. O alcance do conceito de mobilidade sustentável se dará pela adoção de medidas voltadas para a redução do uso individual do automóvel nas vias urbanas e, com isso se reduzir congestionamentos e melhorar as condições ambientais das cidades. O que só será possível com a existência de prioridade aos transportes públicos ofertando serviços de qualidade, também com a priorização dos transportes ativos nos espaços públicos, entendidos como instituições do Comum e, portanto, pertencentes a todos. Além de se repensar os modelos de planejamento urbano das cidades a nível urbano-metropolitano, fortalecendo a economia de vizinhança integrada com o uso compartilhado de veículos através de tecnologias digitais, de modo que as pessoas possam realizar suas atividades próximas aos seus locais de moradia sem necessidade de uso frequente do carro para se deslocar.

Em quarto lugar, se coloca a necessidade de uma gestão integrada das infraestruturas e suas redes no planejamento e gestão das cidades. O transporte público e a mobilidade devem ser pensados de forma integrada com as políticas ambientais, e de habitação, saneamento, energia e internet, de modo que a cidade e seu território urbano-metropolitano possa ser pensada e vivida pela população em condições de atender aos 17 Objetivos do Desenvolvimento Sustentável. Isso ocorrendo, teremos cidades resilientes, seguras e sustentáveis.

Em quinto lugar, com base nas experiências relatadas por Banister (2008), se coloca a questão da estratégia a ser seguida pela liderança na condução da política. Devem-se buscar os elementos-chaves de aceitação da inovação de associar a mobilidade sustentável à gestão e controle da sociedade. Essas estratégias passam por: i) uma comunicação eficaz com a sociedade mostrando as mudanças e os resultados que se pretendem; ii) uma implementação da política em etapas; iii) integração com outras políticas públicas, principalmente de planejamento do uso do solo e de gerenciamento da demanda e iv) avaliação permanente dos resultados para realizar sempre que oportuno, os ajustes necessários. 
As experiências analisadas nesse artigo mostram a importância da construção da confiança entre acadêmicos, profissionais e políticos, para que levem suas reflexões, em especial, aos prefeitos das cidades. Esperamos que nossos prefeitos compreendam as diretrizes estratégicas aqui expostas e tenham espírito público e compromisso suficiente com seu povo para implantar ações voltadas para a mobilidade sustentável e qualidade de vidas em nossas cidades, com participação efetiva da sociedade, visando no futuro, mais autonomia para uma gestão compartilhada.

Agradecimentos: Os autores agradecem ao Conselho Nacional de Desenvolvimento Científico e Tecnológico (CNPq) e à Fundação de Amparo à Ciência e Tecnologia do Estado de Pernambuco (FACEPE) pelo apoio financeiro e incentivo à realização desta pesquisa. 


\section{O Bibliografia}

"Aragão, J.; Brasileiro, A.; Morais, A. C.; Yamashita, Y. e Consulin, R. F. (2020). Public And Private Agents In Waterway Transport Development: The Experience Of Wallonia (Belgium). Archives of Business Research, v. 08, p. 238250, 2020.

» Aragão, J.; Yamashita, Y.; Brasileiro, A. e Moraes, C. (2017). Elements of Advocacy in Transport Policy Formulation. Archives of Business Research, v. 5, p. 72-88, 2017.

»Banister, D. (2008). The sustainable mobility paradigm. Transport policy, 15(2), 73-80.

" Billiard, I. (1986) L'espace public. In: Les Annales de la recherche urbaine, $\mathrm{N}^{\circ} 32$, 1986. Compositions urbaines, 87-94; doi: https://doi.org/10.3406/ aru.1986.1279. Disponível em: https://www.persee.fr/doc/aru_0180930x_1986_num_32_1_1279.

» Bobbio, N. (2000). Teoria geral da Política, Ed. Campus, São Paulo.

»Braga, R. (2017). A rebeldia do precariado : trabalho e neoliberalismo no Sul global, Boitempo Editora, São Paulo.

"Brasileiro, A. (1991). Développement urbain et transports collectifs. Enseignementos des expériences de Recife et Curitiba, thèse de doctorat, École Nationale des Ponts et Chaussées, Paris.

» Brasileiro, A. (2019). Instituições, grupos de interesse e sua liderança em projetos de transportes, Projeto UFPE/CNPq, Recife.

»Broca, S (2017) A defesa dos bens comuns, ¿uma bandeira agregadora para a esquerda?, in Le Monde Diplomatique, 17 fevereiro 2017.

»Brossaud, C. e Fiori, S. e Simay, P. (2019). "Les communs urbains : nouveau droit de cité?», Métropolitiques, 13 juin 2019. URL: https://metropolitiques.eu/ Les-communs-urbains-nouveau-droit-de-cite.html.

»Courty, G. (2006). Les Groups d'intérêt, Editions La Découverte, Repères, Paris.

»Dardot, P. e Laval, C. (2017). Comum: Ensaio sobre a revolução no século XXI, Ed. Boitempo, São Paulo.

»Desgoutte,J.(2019). “Les commons en friche, in "Les communs urbains: nouveau droit de cité?», Métropolitiques, 13 juin 2019. URL: https://metropolitiques.eu/ Les-communs-urbains-nouveau-droit-de-cite.html.

» Galla, P. (2003). Teoria institucional de Douglas North, in Revista de Economia Política, Vol. 23, Nº2 (90), abril-junho.

" Grossman, E. e Sauragger, S. (2006). Les groupes d'intérêt. Action collective et stratégies de représentation, Armand Colin, Paris.

》 Harvey, D. (2011). Le capitalisme contre le droit à la ville, Ed. Amsterdam, Paris.

» Harvey, D. (2020). Política anticapitalista em tempos de coronavírus, publicado em 24/03/2020, Jacobin Brasil.

" Holden, E.; Banister, D.; Gössling, S.; Gilpin, G. e Linnerud, K. (2020). Grand Narratives for sustainable mobility: A conceptual review. Energy Research $\&$ Social Science, 65, 10145 . 
» Holden, E.; Geoffrey, G. e Banister, D. (2019). Sustainable Mobility at Thirty. Sustainability 2019, 11, 1965; doi:10.3390/su11071965.

" Kishimoto, S.; Steinfort, L. e Petittjean, O. (2020). The future is public. Towards democratic ownership of public services, Amsterdam and Paris.

》Lefebvre, H. (1968). Le droit à la ville, Paris, Anthropos.

"Lucarelli, A. (2018). Biens communs. Contribution à une théorie juridique, in Droit et société, 2018/1/N ${ }^{\circ} 98$, pages 141 à 157, https://www.cairn.info/revuedroit-et-societe-2018-1-page-141.htm.

» Matei, U. (2011). Rendre inaliénables les biens communs, in Le Monde Diplomatique, Dezembro 2011.

" Muller, P. e Surel, Y. (2000). L'analyse des politiques publiques, Ed. Montchrestien, Paris.

" North, D. C. (2018). Instituições, mudança institucional e desempenho econômico, Três Estrelas, São Paulo.

»Occupy (2012). Movimentos de protestos que tomaram as ruas, Boitempo Editora e Carta Maior, São Paulo.

" OECD (Organisation for Economic Cooperation and Development) (2002). Global long term projections for motor vehicle emissions (MOVE II) project. Working Paper on National Environmental Policy. Working Group on Transport, ENV/EPOC/WPNEP/ T(2002)8/REV1, Paris.

»Ostrom, E. (1990). Governing the Commons. The Evolution of Institutions for Collective Action, Cambridge University Press.

»Ostrom, E. (2010). Gouvernance des biens communs. Pour une nouvelle approche des ressources naturelles, De boeck Supérieure s.a. Bruxelles.

»Paquot, T. (2009). L'espace public, Editions La Découverte, Paris.

»Passerelle (2012). Os bens comuns. Modelo de gestão dos recursos naturais, Revista Passerelle Nº6/2012, www.Coredem.info.

»Santos, E. (2000). Concentração em mercados de ônibus urbanos no Brasil: Uma análise do papel da regulamentação. Tese de doutorado, Programa de Engenharia de Transportes/COPPE /UFRJ, Rio de Janeiro.

"Shimoto, S.; Lobina, E. e Petittjean, O. (2015). Eau publique, eau d'avenir, L'expérience mondiale de la remunicipalisation, sous la direction de, Paris.

»Sindi, A. (2014). L'Eau de Paris. Retour vers le public, Eau de Paris, Paris.

» Terranova Think Tank (2020). Le Manifeste Pour Paris (Anne Hidalgo, Maire de Paris et David Belliard, Président du groupe écologiste de Paris, 16 juin 2020, www.tnova.fr.

»The World Bank (2010). Coalition building. Communication for Governance and Accountability Program (CommGAP). Washington, DC: World Bank. Documento Web (acessado em 2/o9/2017): http://documents.worldbank.org/curated/ en/301231468332369676/Coalition-building.

\section{Anísio Brasileiro / anisio.brasileiro@ufpe.br}

Engenheiro Civil pela Universidade Federal de Pernambuco (UFPE-1977). Mestre em Engenharia Industrial pela Pontifícia Universidade Católica do Rio de Janeiro (1980). 
Doutor em Engenharia de Transportes pela École Nationale des Ponts et Chaussées (1996). Pós-Doutorado no Laboratoire Techniques, Territoires et Sociétés, Paris (2000) -Professor e pesquisador na UFPE. Bolsista de produtividade do CNPq- PQ I-D Tem pesquisas nas áreas de Economia da Regulação. Gestão dos Serviços Urbanos, Economia dos Transportes. Ex Reitor da UFPE. Membro da Academia Pernambucana de Ciências e da Academia Pernambucana de Engenharia.

\section{Leonardo Herszon Meira / leonardo.meira@ufpe.br}

Engenheiro Civil pela Universidade Federal de Pernambuco (UFPE-2003). Mestre e Doutor em Engenharia Civil, área de Transportes e Gestão das Infraestruturas Urbanas (UFPE-2007 e 2013). Professor e pesquisador na UFPE. Atualmente coordenador do Programa de Pós-Graduação em Engenharia Civil da UFPE. Bolsista de produtividade do CNPq - PQ 2. Tem pesquisas nas áreas de Mobilidade Urbana, Planejamento de Transportes. Engenharia de Tráfego.

\section{Ligia Rabay / ligia.rabay@ufpe.br}

Engenheira Civil pela Universidade Federal da Paraíba (2016). Mestre em Engenharia Civil, área de Transportes e Gestão das Infraestruturas Urbanas (UFPE, 2019). Doutorado em andamento em Engenharia Civil na UFPE na área de Transportes e Gestão de Infraestruturas Urbanas (iniciado em 2019). Atua principalmente nos seguintes temas: transporte público, gerenciamento da demanda, economia dos transportes e mobilidade urbana. Atualmente é professora substituta na UFRN.

\section{Natália Cavalcanti / natalia.cavalcanti@ufpe.br}

Engenheira Civil pela Universidade Federal de Pernambuco (2016). Mestre em Engenharia Civil, área de Transportes e Gestão das Infraestruturas Urbanas (UFPE, 2017). Doutorado em andamento Engenharia Civil na UFPE na área de Transportes e Gestão de Infraestruturas Urbanas (iniciado em 2020). Atua principalmente nos seguintes temas: transporte público, gestão de pavimento, economia dos transportes e mobilidade urbana.

\section{Pâmmela Roberta Gonçalves dos Santos / pammela.santos@ufpe.br}

Engenheira Civil pela Universidade Federal de Pernambuco (2015). Mestre em Engenharia Civil, área de Transportes e Gestão das Infraestruturas Urbanas (UFPE, 2017). Doutorado em andamento Engenharia Civil na UFPE na área de Transportes e Gestão de Infraestruturas Urbanas (iniciado em 2020). Atua principalmente nos seguintes temas: transporte público, tecnologias de informação, mobilidade para pessoas com deficiência e segurança pública nos transportes. 